\title{
Pre-diagnostic and Diagnostic Stages of Autism Spectrum Disorder: A Parent Perspective
}

\author{
Venus Wong, Yue Yu, Melissa L. Keyes and John H. McGrew
}

Parents of children with autism spectrum disorder (ASD) experience greater stress than parents of neurotypical children and of children with other types of disabilities (Benson \& Kersh, 2011; Bristol, 1987; Dabrowska, 2010). Caregiver stress varies over time as the child ages and may be particularly high during key transition points (Baxter, Cummins, \& Polak, 1995; Stuart \& McGrew, 2009). For children with a disability, one such critical transition point is receiving the diagnosis (Abbott, Bernard, \& Forge, 2012; Evan, 2010). However, little research has examined the diagnostic process comprehensively (Braiden, Bothwell, \& Duffy, 2010). Available studies provide a preliminary picture of the diagnostic experience of children with ASD and their parents as they progress through the prediagnostic, diagnostic, and post-diagnostic phases. During the prediagnostic phase, parents begin to notice problems with their children but also report great uncertainty, confusion and despair about the problem and its severity (Midence \& O'Neill, 1999). Parents report developmental concerns as early as 18 months of age (Howlin \& Moore, 1997; Midence \& O’Neill, 1999), and most recognize a problem by age three (Goin-Kochel \& Myers, 2005). Language and communication delay are the main factors arousing parental concerns (Kozlowski, Matson, Horovitz, Worley, \& Neal, 2011).

During the diagnostic process, parents continue to express confusion and uncertainty (Braiden et al., 2010). The diagnostic process typically involves multiple professionals, with only limited communication with parents, leaving many feeling unadvised, uninformed, and dissatisfied (Braiden et al., 2010; Selimoglu, Ozdemir, Toret, \& Ozkubat, 2013). Not uncommonly, parents report receiving an incorrect diagnosis for their child, such as profoundly deaf or fragile X syndrome (Midence \& O’Neill, 1999). Parents also report being bounced back and forth among professionals, before finally getting help from autism specialists (Midence \& O’Neill, 1999). Parents also experience strong emotional reactions (Mansell \& Morris, 2004). Some feel anxious, stressed, and sad throughout the process, whereas others feel relieved, angry, and shocked after receiving the diagnosis (Benson \& Karlof, 2009; Hutton \& Caron, 2005; Meadan, Halle, \& Ebata, 2010; Volkmar, Paul, Klin, \& Cohen, 2005). A positive and supportive consultation style can help alleviate the negative impacts of the diagnosis (Abbott et al., 2012).

During the post-diagnostic period, some parents report receiving needed services and having a better understanding of their children's conditions (Midence \& O'Neill, 1999), whereas others struggle with unmet needs for themselves and their child (e.g., a lack of quality services and professional support; Selimoglu et al., 2013). Moreover, parents continue to need and seek information through professionals, peers, and other sources (e.g., internet, books) (Mansell \& Morris, 2004).

This is the author's manuscript of the article published in final edited form as: Wong, V., Yu, Y., Keyes, M. L., \& McGrew, J. H. (2017). Pre-diagnostic and Diagnostic Stages of Autism Spectrum Disorder: A Parent Perspective. Child Care in Practice, 23(2), 195-217. http://dx.doi.org/10.1080/13575279.2016.1199537 
Although extant studies have added to our knowledge of the diagnostic process in ASD, significant limitations exist. For example, most studies have been small in scale (i.e., sample sizes < 50) (e.g., Midence \& O'Neill, 1999) and conducted in non-U.S. countries with very different health systems that may produce very different diagnostic experiences (e.g., Abbott et al., 2012; Braiden et al., 2010; Brog \& Knussen, 2006; Giacomo \& Fombonne, 1998). Moreover, most studies are retrospective (see Brogan \& Knussen, 2003; Osborne, McHugh, Saunders, \& Reed, 2008), often interviewing parents of individuals with ASD years after the initial diagnosis, introducing potential biases in recall. Studies also have tended to rely exclusively on either qualitative or quantitative methods. Mixed methods designs, however, are preferable because they can provide a richer understanding of context and individual experience (see Abbott et al., 2013). In the current study, we wanted to understand the diagnostic process, its impact, and factors that modify parental experiences of obtaining a diagnosis of ASD. We analyzed quantitative and qualitative data and used this data to develop a model of the diagnostic process.

\section{Methods}

\section{Participants}

Seventy-eight participants were recruited through local diagnostic centers. Participants were caregivers of a child diagnosed with ASD within six months of data collection by a licensed psychologist or medical doctor. Participants' mean age was 35.0 and the vast majority were white $(94.9 \%)$ and female $(98.7 \%)$. Thirty-three percent had a college degree. Most participants reported an annual household income below $\$ 60,000(59.5 \%)$.

\section{Measures}

Demographic information. Information was collected about parents' and children's educational levels, age, gender, and household income.

Diagnostic process. Diagnostic process was measured using two novel questionnaires created for the study. The first was a quantitative questionnaire intended to assess the positive and negative experiences of receiving a diagnosis of ASD. Items were based on 26 commonly expressed themes related to receiving a diagnosis reported by caregivers of children recently diagnosed with an ASD (Mansell \& Morris, 2004). The resulting questionnaire, Obtaining Diagnosis Questionnaire (ODQ; Stuart \& McGrew, 2009), had 26 items covering 13 positive experiences and 13 negative experiences, forming two subscales. Items were rated using a 5point Likert scale $(0=$ strongly disagree to $4=$ strongly agree $)$. Internal consistency estimates were adequate for both the positive $(\alpha=0.77)$ and negative experiences $(\alpha=0.81)$ subscales.

\section{Insert Table 1 about here}

Autism symptom severity. The 42-item Gilliam Autism Rating Scale, Second Edition (GARS-2; Gilliam, 2006) was used to confirm the autism diagnosis and assess autism symptom 
severity. The GARS-2 produces three subscale scores (i.e., stereotyped behaviors, communication, and social interaction), a standardized Autism Index $(M=100 ; S D=15)$, and has good internal consistency $(a=0.94)$ and test-retest reliability $(r=0.88)$ (Gilliam, 2006). For the current study, the internal consistency was .93 , and the mean $(M=100.90, S D=18.28)$ was not significantly different from the standardization sample $(M=100, S D=15, n=1107 ; t(1184)$ $=.51, p=.61)$. Scores greater than 85 on the Autism Index indicate an individual is likely to have autism (Gilliam, 2006).

Parent social support. General social support was measured using the 12-item MultiDimensional Scale of Perceived Social Support (MSPSS; Zimet et al., 1988). Items are rated using a 7-point Likert scale ( 1 = very strongly disagree to $7=$ very strongly agree). The MSPSS measures perceived social support, e.g., 'My family really tries to help me.' The internal consistency was excellent $(\alpha=0.95$ ). Contextual social support (i.e., support from other families within the ASD community and professionals providing support to children with ASD and their parents) was measured using the Contextual Perceived Social Support (CPSS). The CPSS is an eight-item questionnaire. Items are rated using the 7-point Likert scale $(1=$ very strongly disagree to $7=$ very strongly agree). The internal consistency estimate of the CPSS was good $(\alpha$ $=0.88)$ (Stuart \& McGrew, 2009).

Parent mental and physical health functioning. Mental and physical health-related functioning were measured with the 12-item Short-Form 12 (SF-12; Ware, Kosinski, \& Keller, 1996). The SF-12's eight subdomains were transformed into physical and mental health functioning scores. The scale contains categorical questions (i.e., yes/ no) as well as three-, five-, and six-point Likert scales. The SF-12 has been used extensively in health research; the physical $(\alpha=.77)$ and mental health life domains $(\alpha=.76)$ have adequate internal consistency (Ware et al., 1996).

Qualitative report of diagnostic process. The 9-item Diagnostic Process Questionnaire (DPQ) was created for the study. Participants provided descriptive information regarding the process of receiving a diagnosis, including eight short answer questions: child's age when concerns first suspected, who first detected the concerns, what behaviors or developmental issues were concerning, to whom the caregiver took their concerns, how many providers were consulted before receiving a diagnosis, how well the caregiver felt his or her concerns were validated by that provider, and the age of the child when he or she received a formal diagnosis of an ASD. A final question asked participants to describe briefly the process of receiving a diagnosis. See Appendix for the full questionnaire.

\section{Analysis}

Quantitative analysis. General descriptive statistics were examined first. Then, bivariately, correlation analysis was used to explore the relationship between wait time and the following potential predictive variables: Social support, autism severity, and mental and physical health functioning. Multivariately, hierarchical stepwise regression analysis was used to predict wait time. Variables significantly or nearly significantly correlated with wait time were included in the regression. Statistical analyses were conducted using SPSS 22.0 (IBM, 2013). 
Qualitative analysis. Seven of the nine DPQ items were converted directly into quantitative data for analysis (e.g., child's age when problem suspected, who first suspected problem). Formal qualitative analysis was required for two DPQ items. Content analysis was utilized for item three (What behaviors or issues in your child gave you concern at the time?). Two authors categorized the data into five domains (i.e., cognitive delay; behavioral, sensory, and/or rigid interests issues; physical and/or motor delay; social and/or emotional delay; and receptive and expressive language and/or communication delay). To check reliability, 20\% of the transcripts were coded independently and compared. Coder interrater reliability (IRR) was good; Kappas ranged from .86 to $1.0(p<.05)$.

Grounded theory was used to analyze data for item nine (i.e., In your own words, please describe the process you and your family went through to receive a diagnosis of an ASD in your child) (Strauss \& Corbin, 1990; Strauss \& Corbin, 1994). Grounded theory is an inductive method that generates theories that explain and explicate plausible relationships among sets of concepts systematically from a set of data. The method is iterative and usually starts from open coding (e.g., labeling and categorizing phenomena from data) and then relates codes to other codes logically. After extracting core concepts and possible theories from data, selective coding and theory sampling coding are conducted. The last step is to develop a theory that fits the data (Strauss \& Corbin, 1990; Strauss \& Corbin 1994; Grounded Theory Institute, 2014).

Initially, one coder read a subsample of the transcripts using open coding and identified 23 recurring concepts, which were developed into a codebook. The codebook author, together with another coder applied the codebook independently to see whether both captured the same recurring concepts from the sample of transcripts. IRR was calculated to confirm coding consistency, which was divided into two parts - training and IRR coding. During the first stage, using ten randomly selected transcripts (i.e., $12.5 \%$ of the total number of the transcripts), coders independently applied the codebook and compared their codes. When there were disagreements, the coders discussed their work to reach $100 \%$ consensus. The codebook was revised to clarify codes when there were areas of disagreement. During the second stage, using a separate sample of $33(41 \%)$ randomly selected transcripts, coders again independently applied the revised codebook. Coders met to discuss disagreements and concerns. The overall Kappa across all codes for this second set of transcripts was .94 .

Finally, coders categorized the 23 codes into a smaller list of broader themes based on their similarities and shared properties (e.g., people, location, timing of events) (see Strauss \& Corbin, 1990). Codes were categorized into possible themes, and each theme was compared against other themes through a process of constant comparison to develop a final set of themes that were comprehensive, exhaustive, clear and exclusive. Coders examined and reexamined the accuracy and exclusiveness of the themes and analyzed the connection and pattern between and among themes. A final set of six core themes was identified.

\section{Results - Quantitative Analysis}

\section{The First One Who Suspected Problems and First One to Whom Parents Reported Problems}


In most cases, the first person to suspect a problem was the participant caregiver $(69.2$ $\%$, followed by relatives $(10.3 \%)$, the child's doctor $(7.7 \%)$, secondary caregivers $(7.7 \%)$, school $(6.4 \%)$, and friends $(3.8 \%)$. The person most often consulted first about their child's problems was their child's medical doctor $(59 \%)$, followed by friends or relatives $(24.1 \%)$. Relatively few participants first brought their concerns to other specialists $(12.8 \%)$ or to their child's school (3.8\%).

\section{Lapse Between First Concern and Diagnosis and Predictors and Outcomes Associated with Wait Time}

Mean time between first concern and diagnosis was 28.72 months $(S D=27.12$, Range $=0$ - 127). Twenty-nine percent of participants obtained the diagnosis within 12 months of the first concern, $24.9 \%$ between $12-24$ months, $15.4 \%$ between $25-36$ months, $4.1 \%$ between $37-48$ months, and $13.9 \%$ took more than 49 months. To understand the impact of parent/child factors on the lapse between first concern and diagnosis (wait time), we examined correlations between wait time and four child-level predictive variables (i.e., overall ASD severity, and severity of stereotyped behaviors, communication, and social interaction), and four parent-level predictive variables (i.e., general and contextual social support, mental health and physical health functioning). Three parent level variables negatively correlated with wait time: contextual social support $(r=-.32, p<.01)$, general social support $(r=-.26, p<.05)$, and physical health functioning $(r=-.31, p<.01)$. One child-level variable (i.e., severity of communication problems) significantly correlated with wait time $(r=.25, p=.051)$. A multiple regression examining predictors of wait time was conducted and included the following predictor variables: child's communication severity, contextual social, general support, and parent physical health functioning. The overall regression model was significant, $\mathrm{F}(4,78)=5.91, p<.0, R^{2}=.24$. Child's communication severity $($ Beta $=-.26, p<.05)$, parent physical health functioning $($ Beta $=$ $-.24, p<.05)$, and contextual support $($ Beta $=-.25, p<.05)$ significantly predicted wait time.

\section{First Concerns}

In the vast majority of cases (68.4\%), caregivers' first concerns focused on language delay (e.g., lack of words). Other common first concerns included social and/or emotional delay $(43.0 \%)$ (e.g., no interest in others), restricted/atypical interests or routines (39.2\%) (e.g., narrowly focused special interest), behavioral issues (36.7\%) (e.g., severe tantrums), sensory issues $(25.3 \%)$ (e.g., tactile sensitivity), cognitive delay (24.1\%)(e.g., slow conceptual development), and physical and/or motor delay (15.2\%)(e.g., delayed fine motor skills).

\section{Parents Experiences Obtaining the Diagnosis of ASD}

We also examined mean ratings of the subscales and individual items on the ODQ. Overall, parents reported significantly more positive experiences $(M=2.66, S D=.4 .24)$ than negative experiences $(M=2.00, S D=.62)$ during the diagnostic process; $\mathrm{t}(77)=6.90, p<.01$. The two subscales also were significantly negatively correlated, $r(78)=-.28, p<.05$, indicating that parents endorsing more positive experience items also tended to endorse fewer negative experience items (Table 1 lists item and subscale means). 


\section{Professional Consulted}

On average, parents reported consulting with $3.3(S D=1.3)$ professionals before receiving an ASD diagnosis. Ten percent reported consulting with one professional before their child obtained a diagnosis, $13.9 \%$ consulted with two professionals, $29.1 \%$ consulted with three professionals, $24.4 \%$ consulted with four professionals, and $21.8 \%$ consulted with five or more professionals.

Parents reported receiving information regarding their child's situation from 18 types of professionals. Most consulted with pediatricians (55.1\%) and psychologists $(41.0 \%)$. Other commonly consulted professionals included neurologists $(29 \%)$ and general physicians $(24.4 \%)$. Less than $4 \%$ of parents consulted audiologists $(3.8 \%)$, geneticists $(3.8 \%)$, counselors $(3.8 \%)$, behavioral interventionists $(3.8 \%)$, nurse specialists $(3.1 \%)$, and social workers $(2.6 \%)$.

Parents also rated professionals' responses to their concerns about their child. Professionals rated least likely to provide minimal diagnostic support (e.g., making referrals) were counselors $(66.7 \%)$, audiologists $(66.7 \%)$, and general physicians/family doctors (45\%) (see Table 2). Professionals rated least likely to validate parents' concerns were: pediatricians $(M=1.75, S D=.80)$, general physicians $(M=1.80, S D=.83)$, counselors $(M=2, S D=1)$, and social workers $(M=2, S D=1.41)(1=$ not at all validated, $2=$ somewhat validated, $3=$ validated; see Table 3).

\section{Insert Table 2 about here}

\section{Insert Table 3 about here}

\section{Results - Qualitative Analysis}

Six core themes were identified from responses to item 9 of the DPQ concerning the process of diagnosis: "heightened awareness," "initial search," "dissatisfaction with medical or associated processionals," "long process/delay," "feeling uninformed," "parent psychological and relational experiences," and "diagnosis goals." Below we provide a brief overview, a more detailed explanation of the qualitative results is available from the first author.

\section{Heightened Awareness}

Heightened awareness refers to parents' awareness of their children's atypical development prior to diagnosis, including initial concerns, seeking social validation for concerns, receiving initial diagnoses other than $\mathrm{ASD}$, and receiving related services or initial services that were inadequate to deal with their problems. Parents consistently reported that their child failed to meet developmental milestones (I had many concerns which I discussed with our PCP. My 
sister (a special education teacher) and my mom confronted me about possible concerns before this). Many parents reported that their child had already received multiple diagnoses or suffered from medical health problems other than ASD (e.g., ADHD, ODD, speech problems, low birth rate) before the ASD diagnosis, which heightened parents' attention to their child's development and needs. At times, parents were already working closely with professionals to whom they could bring issues about their child (Daughter was a 29-week preemie, so we brought symptoms to attention of the therapist who had been following her. We went to an OT consult and got a SID diagnosis.) Parents also sought reassurance or confirmation about their concerns informally within their inner circles (I asked the neighbor, whose sons have ASD, if she saw signs in my son. She did. After a long conversation, I could see the signs in my son. We asked the school to test for ASD.)

Although many children received services for their non-ASD mental health or medical diagnoses, they continued to have negative consequences (e.g., expulsion from schools, an outburst that required in-patient services) that heightened the insufficiency of current support, the need for additional services, and the need for a new diagnosis (Our son was expelled from four daycares before we were able to get him into a behavior modification program).

\section{Initial Search}

Initial search is defined as parents' search for additional information about ASD through easily accessible means and immediately available resources. Parents reported two main sources of information - the Internet or other media (I read all available information and books that were recommended to me, and said, 'Okay, now everything (ASD) makes sense.') and people they knew (e.g., school professionals, friends, or family members) (After a friend's serious urging — she 'knew' my son had autism - I made several appointments with developmental pediatricians in the area.). Parents also sought out specific information regarding evaluations and the diagnosis of ASD and a few began to make appointments with medical or mental health professionals specializing in ASD.

\section{Dissatisfaction with Medical or Associated Professionals}

Dissatisfaction with medical or associated processionals refers to parents' negative feelings towards the diagnostic process. Parents reported two primary areas of dissatisfactiondeferred diagnoses (Kept talking to his doctor at different times about things I thought were a problem, but they never thought it was anything) and poor patient-doctor relationships (My son's first pediatrician thought it was all in my head. He treated me like I was a hypochondriac for my child.). Parents frequently mentioned that medical and associated professionals made the wrong decision for their child. For instance, parents reported that doctors failed to respond appropriately or in a timely manner to their concerns, and that the misjudgment or delayed judgment resulted in a deferred diagnosis.

Many parents reported poor quality doctor-patient interactions. For example, some parents felt insulted (He was the rudest person I have ever met) or ignored by professionals during medical consultation sessions (First, we had to convince the pediatrician that there was something very wrong, which took 3 visits-4-5 months-before he took us seriously. In the end 
he was irritated by us.). Parents also reported mistrust of professionals, especially those not specialized in ASD, and that doctors did not communicate information with them (We were frustrated because ... the medical staff wasn't telling us anything no matter how much we asked. When he was discharged they didn't tell us what kind of adaptations he would need at school or what to do as a family.).

\section{Long Process/Delay}

Long process/delay involves the structural and process barriers that complicate and prolong the diagnostic process. Although some parents reported a fairly straightforward and speedy diagnostic process many other parents mentioned that the diagnostic process was very lengthy. Parents reported three main hurdles to obtaining a diagnosis-wait time to get the first appointment (After only 6 months on the waiting list we were able to get an appointment with a developmental pediatrician), lengthy diagnostic evaluation and testing procedures (Lots of tests. Took a year and a half. Starting with inconclusive hearing testing ... Then went to interviews, MRI, EEG, and DNA tests for fragile X, lead testing. Final piece was a non-verbal child test for autism.), and wait time to get evaluation results/diagnosis or for professionals to agree to a final diagnosis (It was a living nightmare because we could not get all professionals involved to agree on the Autism diagnosis).

\section{Being Uninformed}

Being uninformed refers to parents' lack of knowledge about ASD and related interventions after obtaining an ASD diagnosis. Parents frequently reported feeling uninformed about ASD (At the time of Asperger's diagnosis, I did not know a lot about it) and related services and treatments (This is a big concern as we aren't sure how to proceed next). As a result, they did not know how to proceed or the next step for the child and family.

\section{Interpersonal and Psychological Impacts}

Interpersonal and psychological impacts refers to parents' interpersonal and psychological experiences during the diagnostic process. Parents reported both intra- and interpersonal impacts. Emotionally, parents reported feeling stressed/anxious, frustrated, upset, and sad at various times throughout the process (to come to the realization that she was not going to wake up and be 'normal'one day was very sad for me). In addition, parents reported feeling relieved after their child had received the diagnosis (It was actually a relief to get the diagnosis, as I knew something was wrong with my daughter). Interpersonally, parents reported that relationships with their spouses (This causes a lot of friction with my spouse) and family members sometimes deteriorated during the diagnostic process (My husband is still in denial now and blaming God daily for this... this has caused a big strain on our relationship.).

\section{Reasons to Obtain a Diagnosis}

Reasons to obtain a diagnosis refers to parents' motivation for and purpose in getting an ASD diagnosis. Parents often mentioned the practical benefits of getting a diagnosis, including getting ASD-specific services and funding, which was why they were determined to get the right diagnosis (The diagnoses was really only a way for us to guarantee that we could get him the 
help that he needed, as in the funding from the county, state, whatever, as well as the special schooling that he needed.).

\section{Prediagnostic and Diagnostic Stages}

Research examining the ASD diagnostic process as a whole is scarce (Braiden et al., 2010). Accordingly, we attempted to identify a set of commonly experienced stages characterizing the process of obtaining a diagnosis, building on two existing models outlining general diagnostic stages.

A potential useful model was developed by Andersen and Cacioppo (1995) to understand cancer patients' health seeking behaviors. They postulated five stages of delay in the process of receiving a diagnosis: (a) appraisal delay (the lapse between detection of unexplained symptoms and inference that symptoms reflect illness), (b) illness delay (interval between inference of illness and decision to seek medical help), (c) behavioral delay (time delay in scheduling first medical appointment), (d) scheduling delay (time between scheduling appointment and receipt of medical attention that identifies need for disease-specific testing), and (e) treatment delay (time between testing and start of treatment). The delay across all the stages is called total patient delay (Andersen \& Cacioppo, 1995).

The Andersen and Cacioppo (1995)'s model provided a good fit for our data. For example, deferred diagnosis has been frequently identified as a problem in ASD (Guthrie, Swineford, Nottke, \& Wetherby, 2013; Howlin \& Moore, 1997; Mandell, Novak, \& Zubritsky, 2005). However, the model also had several limitations. First, the model focuses on the patient, not the parent. Second, the diagnostic stages are less clear-cut and last longer for individuals with ASD. There are no definitive laboratory tests for ASD, thus a diagnosis is based on observable manifestations in social, communication, and behavioral deficits during early development (Johnson \& Myers, 2007). Third, in addition to the patient-focused delays addressed by Anderson and Cacioppo, children with ASD and their parents experience systemic delays (e.g., long waiting list; a lot of paperwork and tests) that are out of their control, underlining the lack of services and inefficiency of the current diagnostic system.

Based on our data, then, we identified one additional feature of illness delay, i.e., informational delay, and one additional delay stage, i.e., diagnostic delay. We describe our adapted six-stage model below.

Stage 1 - Appraisal delay. Appraisal delay is defined as the time between the occurrence of unexplained symptoms and parental judgment that these represent atypical development of their children. At this stage, the children display a developmental delay (e.g., speech problems), and family members, friends, and/or parents notice these concerns. Parents may start to talk to others in their immediate or inner social circle to seek informal confirmation about their concerns. Many children in this stage have already received multiple diagnoses (e.g., ADHD) and associated services (e.g., speech therapy). Students may have additional problems, such as being expelled or excluded from typical educational settings (e.g., schools) due to ASDrelated emotional or behavioral disturbance. Parents may start to notice that the existing support is not sufficient. Eventually, parents see that their child is displaying atypical development. 
Stage 2 - Illness and informational delay. Illness delay is defined as the time between parents' assessments that their child manifests atypical development and the decision to seek medical help. Informational delay is an additional step in this process during which parents research possible explanations of their child's atypical development and obtain information about professionals with whom they can consult. Illness and informational delay often occur concurrently as parents' knowledge about solutions and possible actions may affect when they seek formal help from mental health or medical professionals. At this stage, parents search for information while they try to understand the atypicality of their children or seek professional help. However, information regarding autism is often confusing, overwhelmingly negative, and unreliable (Carter, 2009), complicating the process of symptom identification and finding the right professionals. Parents with ASD may go through a longer process to narrow down useful information that helps them better understand ASD and find the right help. Parents usually seek out specific information about ASD, interventions, and other diagnoses from the internet, media, teachers, friends, or family members. The amount, accuracy, and reliability of sources of information may determine the length of illness delay.

Stage 3 - Behavioral delay. Behavioral delay is the time delay between the decision to make an appointment and the actual scheduling of the first medical appointment. At this stage, parents need to take steps to make an appointment with or contact their child's doctors or other professionals (e.g., occupational therapists in schools) in their immediate help circle. Length of behavioral delay is impacted by parents' perceived urgency of the problem, access to health insurance (Mandell et al., 2005; Starfield \& Shi, 2004), access to care (e.g., rural areas have less access to diagnostic services; Murphy \& Ruble, 2012; Thomas \& Holzer, 2006), and access to needed resources to support the process (e.g., financial resources; Mandell et al., 2005). Parents' knowledge about accessible help and ability to seek help from professionals (e.g., access to internet, time to search for diagnostic information and make appointments) are also impact the length of behavioral delay.

Stage 4 - Scheduling delay. Scheduling delay is the time between scheduling an appointment and receipt of medical attention that identifies the need for disorder-specific testing. Parents usually first schedule an appointment with their child's physician to discuss their concerns. Typically, parents do not experience long waits before meeting with their child's primary physician. However, parents often are dissatisfied with the services received. For instance, doctors may not initially share their concerns, which can result in a poor clientpractitioner relationship (e.g., mistrust of physicians). As noted earlier, parents also often report negative experiences with professionals during consultation sessions (e.g., poor physician attitudes; see also Moore, McConkey, Sines, \& Cassidy, 1999). Parents may need to stay in this stage until their physicians agree to refer their child to specialists for a formal autism evaluation. Alternately, parents may switch physicians and go to multiple places as they seek a proper referral. Getting medical attention can be compounded by a doctor's lack of knowledge of ASD, ineffective communication between doctors and parents, poor parent-doctor relationships, and the severity of the ASD symptoms. 
Further delays can occur after obtaining an official referral for an ASD-specific evaluation; parents often report being referred to multiple specialists. Thus, parents may reexperience a behavioral delay in making the ASD evaluation appointment(s) (stage three) as well as a scheduling delay. That is, stage 3 and stage 4 can be recurring for ASD evaluations because of the complex nature of ASD and a lack of certainty about the diagnostic process. In addition, parents often experience dissatisfaction towards the diagnostic system, especially the long waiting lists. Parents enter the next stage once they attend their first ASD-specific diagnostic meeting.

Stage 5 - Diagnostic delay. Diagnostic delay is defined as the time between the first meeting with ASD-specialized professionals and receiving a diagnosis. As noted earlier, the unknown etiology of ASD complicates the diagnostic process, contributing toward diagnostic delay. Unlike disorders with a clearer etiology, ASD diagnosis relies on parent interviews, rating scales, and child behavioral observations. Parents and children may need to visit multiple places and undergo a series of tests and provide extensive information on developmental history to confirm the diagnosis of ASD and rule out other neurodevelopmental disorders. Further, parents often report the need for a lot of paperwork and a long wait time for an official diagnosis and evaluation report (see also Johnson \& Myers, 2007). Conflicting opinions about the ASD diagnosis sometimes occur, which can delay the receipt of an ASD diagnosis. Parents and their children with ASD may go through some diagnostic stages multiple times because of misdiagnoses and referrals. Thus, there may be a feedback loop from diagnostic delay back to informational delay and scheduling delay as parents cycle through the stages several times before they get the final diagnosis.

Stage 6 - Treatment delay. Treatment delay is defined as the time between receipt of the ASD diagnosis and the start of treatment. This stage is impacted by diagnostic delay because doctors or clinicians are not sure about what treatment to prescribe without a definite diagnosis. Moreover, the ASD diagnosis critically affects eligibility to obtain necessary support and services. However, even after issuing a diagnosis, many diagnosticians (mainly physicians) do not communicate information about the diagnosis and associated services with parents. Therefore, parents may still lack relevant knowledge about the next step for interventions. Connections between agencies (e.g., clinics, schools, intervention centers, parent support groups), the availability of information regarding interventions, and the practitioner's postdiagnostic support play critical roles in linking parents to appropriate services in a timely manner.

\section{Discussion}

The study provides a snapshot of parents' experiences before and during the diagnostic process and proposes a model of the diagnostic process organized around six delay stages. The study improved on prior studies by recruiting a fairly large sample of parents, controlling for potential recall bias by requiring that all children had received an ASD diagnosis within the past six months and by utilizing both quantitative and qualitative methods. Overall, our results confirmed and extended findings from prior research. 
In terms of the overall diagnostic process, in the vast majority of cases, parents were the first people to notice problems with their child's development. Once they noticed problems, parents were most likely to contact their child's physician first, highlighting the importance of the role of medical professionals in supporting parents and facilitating the diagnostic process (see Goin-Kochel \& Myers, 2005; Young, Brewer, \& Pattison, 2003). However, parents also reported the need to seek out multiple professionals about their concerns, consulting, on average, 3.3 professionals before receiving an ASD diagnosis. Consistent with the existing literature (Chawarska et al., 2006; Yirmiya \& Charman, 2010), parents reported that language and/or communication delay was the developmental issue most frequently raising concerns.

Of particular concern, however, was the long time, averaging nearly 29 months, between first concern and diagnosis. Because service provision generally requires a confirmed diagnosis, this long lapse potentially translates into children missing valuable early intervention opportunities. Unfortunately, ours is not an isolated finding. The wait time from the current sample (28.7 months) was nearly identical to that reported from a large national study (28.3 months; Rosenberg, Landa, Law, Stuart, \& Law, 2011), suggesting that long wait times are commonplace, although there also was considerable variability in wait time. In contrast to some recent studies, overall ASD severity was not associated with wait time to receive a diagnosis (see Huerta \& Lord, 2012; McMorries, Cox, Hudson, Liu, \& Bebko, 2013). However, children with more severe communication problems did experience a longer wait time for an official diagnosis. Some children, such as non-verbal children with ASD may require more tests to confirm the diagnosis (see Huerta \& Lord, 2012).

Although rarely examined in prior studies, social factors were associated with the diagnostic experience in the current study. Specifically, the greater the perceived parental social support from autism-specific sources, the shorter the wait time. Logically, professionals and people who know ASD may be better able to direct parents to the right places for evaluation and refer parents to professionals that have a good connection with the autism community.

Interestingly, increased contextual support also has been associated with decreased caregiver burden (McGrew \& Keyes, 2014; Stuart \& McGrew, 2009).

Parents with better physical health functioning also reported shorter wait times. The healthier the parents, the shorter the wait time for an official ASD diagnosis. However, the causal direction of the association is not clear. One possibility is that parents with poorer physical health functioning may not have the physical resources to confront the often difficult process of obtaining a diagnosis, leading to longer wait times. Alternately, the stress of longer wait times may directly and negatively impact parents' physical health, leading to a deterioration in their quality of life and ability to take care of their children. This latter interpretation is consistent with reports that caregivers of children with ASD have decreased well-being (Lickenbrock, Ekas, \& Whitman, 2011) and poorer health-related quality of life (Khanna et al., 2011), and would suggest that problems with obtaining quality services, such as a timely diagnosis, may be a factor in poorer parent functioning. However, because it is not clear whether the poor physical health functioning precedes or follows from the longer wait times, a longitudinal study is needed to more definitively understand the direction of these results. 
Professionals' responses to concerns were quite varied and often frustrating for parents. Consistent with the literature indicating a need to train general practitioners (Golnik, Ireland, \& Borowsky, 2009; Noland \& Gabriels, 2004), the current study found that although pediatricians and general physicians were most likely to be contacted initially, parents also rated them as least likely to validate their concerns and provide a diagnosis or appropriate referral. Instead, parents reported a greater likelihood of having their concerns validated and of receiving a diagnosis or referral from specialized professionals (e.g., psychologists, psychiatrists). These findings are consistent with the literature showing that compared to experts who are specialized in child development and mental health, general practitioners (e.g., family doctors, general pediatricians) are less confident and have less knowledge in diagnosing autism (see Dosreis, Weiner, Johnson, \& Newschaffer, 2006; Golnik et al., 2009; Heidgerken, Geffken, Modi, \& Frakey, 2005; Schwartz \& Drager, 2008), and may not be able to refer parents to appropriate professionals or assist the family in a timely manner. Although parents identified some mid-level providers, such as nurse specialists and behavioral interventionists, as helpful in recognizing autistic symptoms and validating concerns, their qualifications limited their abilities to provide a definite diagnosis.

Overall, these data provide a more detailed examination of the involvement of and quality of services provided by different professionals. Three general conclusions are suggested by these data: (a) many types of professionals are involved in the prediagnostic and diagnostic process; (b) parents often do not receive necessary referrals and validation from professionals, especially those not specialized in ASD (e.g., general pediatricians, counselors); and (c) some professionals (e.g., family doctors, pediatricians, counselors) may be hurdles to an effective and efficient diagnostic process. Although additional studies are needed to confirm our findings, the results suggest, at a minimum, that additional training may be needed in the medical and educational fields (Golnik et al., 2009; Noland \& Gabriels, 2004).

We also examined the impact of receiving a diagnosis on parents. As expected, parents reported several negative experiences (e.g., worry) associated with receiving a diagnosis. However, consistent with the literature, parents did not strongly endorse any negative impact (see also Braiden et al., 2010; Midence \& O'Neill, 1999). Some parents also reported shock at the diagnosis and that other people may treat their child worse after getting the diagnosis. Interestingly, however, in contrast to prior studies (e.g., Benson \& Karlof, 2009; Gray, 2003; Hutton \& Caron, 2005 ), most parents in the current sample did not report being particularly angry or shocked about the diagnosis. Moreover, even though they expressed worry, most did not think that the future was necessarily bleak for individuals with ASD. Several reasons may explain these differences. First, many prior studies reporting increased anger and shock were conducted outside the United States (e.g., Gray, 2003; Gupta \& Singhal, 2005; Heiman, 2002; Higgins, Bailey, Pearce, 2005; Hutton \& Caron, 2005). Differences in media coverage, views toward disabilities (e.g., stigma), protection by law, and availability of services may contribute to different reactions toward the diagnosis of ASD (Forlin, Sharma, \& Loreman, 2007; Ng, 1997; Westbrook, Legge, Pennay, 1993). Second, our data were collected concurrently, within six months of obtaining the diagnosis, whereas many prior studies collected data retrospectively, often years following the actual diagnosis (see Brogan \& Knussen, 2003). Reports of emotions about diagnosis obtained retrospectively may be contaminated by recall bias or later difficult 
experiences with the child. Third, the tremendous increase in the number of ASD diagnoses coupled with increased reports of autism in the popular media has led to increased public awareness of autism, which may make the diagnosis of autism seem less unusual and therefore easier to accept. Fourth, compared to other studies, which typically used general measures of negative emotions (e.g., anger), the current study used questions about emotional reactions to the ASD diagnosis. For instance, Benson and Karlof (2009) reported that parents of children with ASD experienced increased anger in general (e.g., felt angry/annoyed, yelled at someone), but failed to measure diagnosis-specfic anger. Thus, differences in culture, contemporary understandings of autism, measurement, and sampling may contribute to the discrepancies in the reports of anger and shock.

Consistent with the relatively low levels of negative experiences, many parents viewed receiving a diagnosis of ASD as having positive impacts for their lives. For instance, parents reported having a better understanding of their child's behaviors. They also reported that the diagnosis relieved some of their sense of blame and that they were better able to get practical help. Also, in contrast to the lowered parental expectations associated with children's disabilities generally (Jackson, 1994; Russell, 2003), parents reported that they did not necessarily lower their expectations for their child and tried to stay positive.

\section{Conclusions}

Overall, the findings provide insight into parents' experiences and barriers to a more efficient diagnostic process, and suggest several possible solutions to improve parents' diagnostic experience. First, although parents acquire initial information about ASD through immediate, accessible sources (e.g., internet and social circles), these sources of information may not be accurate and/or useful. Thus, the implementation and support of multiple media sources for accurate information concerning ASD, including referrals for diagnostic and treatment services, could be helpful (e.g., informational brochures for parents, organizing community activities, and qualified experts speaking in the media). Second, training concerning ASD for general practitioners is needed to decrease delays in obtaining a diagnosis and treatment and increase parents' perceived support from medical professionals (Krauss, Gulley, Sciegay, \& Wells, 2003). Third, better training for educators and educational staff may be helpful in reducing reported low levels of parental support throughout the diagnostic process because almost every child receives services from schools (Palmer, Blanchard, Jean, \& Mandell, 2005). As the only universally mandated and free service for all children, schools can be a reliable source of parental information regarding ASD and feedback about their child's learning. Moreover, better home, school, and community collaboration and well-trained educators may facilitate the early identification of symptoms and referrals (Palmer et al., 2005). Fourth, better collaboration among clinics may help to maximize the currently available resources. For instance, sharing information among clinics with consent from parents may decrease the paperwork that parents need to fill out and in turn shorten the diagnostic process. Usually, the shorter the diagnostic process, the more satisfied the parents (Goin-Kochel, Mackintosh, \& Myer, 2006). Finally, attention needs to be paid to parents' mental health (e.g., stress level) and spousal relationships during the diagnostic period (see Koegel et al., 1992; McGrew \& Keyes, 
2014). The impact of the child's diagnosis extends to the entire family, and both the child and the family may profit from health interventions (Sanders \& Morgan, 1997). 


\section{References}

Abbott M, Bernard P and Forge J (2012) Communicating a diagnosis of Autism Spectrum Disorder-a qualitative study of parents' experiences. Clinical Child Psychology and Psychiatry 18(3): 370-382.

American Psychiatric Association (2013) Diagnostic and Statistical Manual of Mental Disorders (5th ed.). Washington, DC: APA.

Andersen BL, Cacioppo J and Roberts DC (1995). Delay in seeking a cancer diagnosis: delay stages and psychophysiological comparison processes. British Journal of Social Psychology 34 : 33-33.

Banach M, Iudice J, Conway L and Couse LJ (2010) Family support and empowerment: Post autism diagnosis support group for parents. Social Work with Groups 33(1): 69-83.

Baxter C, Cummins, RA and Polak S (1995) A longitudinal study of parental stress and support: From diagnosis of disability to leaving school. International Journal of Disability, Development and Education 42(2): 125-136.

Benson PR ans Karlof KL (2009) Anger, stress proliferation, and depressed mood among parents of children with ASD: A longitudinal replication. Journal of Autism and Developmental Disorders 39(2): 350-362.

Benson P and Kersh J (2011) Marital quality and psychological adjustment among mothers of children with ASD: Cross-sectional and longitudinal relationships. Journal of Autism and Developmental Disorders 41: 1675-1685.

Braiden HJ, Bothwell J and Duffy J (2010) Parents' experience of the diagnostic process for autistic spectrum disorders. Child Care in Practice 16(4): 377-389.

Bristol MM (1987) Mothers of children with autism and communication disorders: Successful adaptation and the double ABCX model. Journal of Autism \& Developmental Disorders 17: 469-486.

Brogan CA and Knussen C (2003) The disclosure of a diagnosis of an autistic spectrum disorder determinants of satisfaction in a sample of scottish parents. Autism 7(1): 31-46.

Carter I (2009) Positive and negative experiences of parents involved in online self-help groups for autism. Journal on Developmental Disabilities 15(1): 44-52.

Chawarska K, Paul R, Klin A, Hannigen S, Dichtel LE and Volkmar F (2007) Parental recognition of developmental problems in toddlers with autism spectrum disorders. Journal of Autism and Developmental Disorders 37(1): 62-72.

Dabrowska A (2010) Parenting stress and coping styles in mothers and fathers of pre-school children with autism and Down syndrome. Journal of Intellectual Disability Research 54(3): 266 -280 . 
Davis NO and Carter AS (2008) Parenting stress in mothers and fathers of toddlers with autism spectrum disorders: Associations with child characteristics. Journal of Autism and Developmental Disorders 38(7): 1278-1291.

De Giacomo A and Fombonne E (1998) Parental recognition of developmental abnormalities in autism. European Child \& Adolescent Psychiatry 7(3): 131-136.

Dosreis S, Weiner CL, Johnson L, \& Newschaffer CJ (2006) Autism spectrum disorder screening and management practices among general pediatric providers. Journal of Developmental \& Behavioral Pediatrics 27(2): S88-S94.

Forlin C, Sharma U, \& Loreman T (2007) An international comparison of pre-service teacher attitudes towards inclusive education. Disability Studies Quarterly, 27(4). Available at http://dsqsds.org/article/view/53/53

Gilliam JE (2006) Gilliam Autism Rating Scale (2nd ed.). TX: Pro-ed

Goin-Kochel RP and Myers BJ (2005) Parental report of early autistic symptoms: Differences in ages of detection and frequencies of characteristics among three autism-spectrum disorders. Journal on Developmental Disabilities 11(2): 21-39.

Goin-Kochel RP and Myers BJ (2005) Parental report of early autistic symptoms: Differences in ages of detection and frequencies of characteristics among three autism-spectrum disorders. Journal on Developmental Disabilities 11(2): 21-39.

Goin-Kochel RP, Mackintosh VH and Myers BJ (2006) How many doctors does it take to make an autism spectrum diagnosis?. Autism 10(5): 439-451.

Golnik A, Ireland M and Borowsky IW (2009) Medical homes for children with autism: A physician survey. Pediatrics 123(3): 966-971.

Golnik A, Ireland M and Borowsky IW (2009) Medical homes for children with autism: A physician survey. Pediatrics 123(3): 966-971.

Gray DE (1994) Coping with autism: Stresses and strategies. Sociology of Health \& Illness 16(3): 275-300.

Gray DE (2003) Gender and coping: the parents of children with high functioning autism. Social Science \& Medicine 56(3): 631-642.

Grounded Theory Institute. (2014) What is grounded theory? Available at http://www.groundedtheory.com/what-is-gt.aspx

Gupta A and Singhal N (2005) Psychosocial support for families of children with autism. Asia Pacific Disability Rehabilitation Journal 16(2): 62-83.

Guthrie W, Swineford LB, Nottke C and Wetherby AM (2013) Early diagnosis of autism spectrum disorder: stability and change in clinical diagnosis and symptom presentation. Journal of Child Psychology and Psychiatry 54(5): 582-590. 
Hayes SA and Watson SL (2013) The impact of parenting stress: A meta-analysis of studies comparing the experience of parenting stress in parents of children with and without autism spectrum disorder. Journal of Autism and Developmental Disorders 43(3): 629-642.

Heidgerken AD, Geffken G, Modi A and Frakey L (2005) A survey of autism knowledge in a health care setting. Journal of Autism and Developmental disorders 35(3): 323-330.

Heiman T (2002) Parents of children with disabilities: Resilience, coping, and future expectations. Journal of developmental and physical disabilities 14(2): 159-171.

Higgins DJ, Bailey SR and Pearce JC (2005) Factors associated with functioning style and coping strategies of families with a child with an autism spectrum disorder. Autism 9(2): 125137.

Holsti OR (1969) Content Analysis for the Social Sciences and Humanities. Reading: AddisonWesley.

Howlin P and Asgharian A (1999) The diagnosis of autism and Asperger's syndrome: Findings from a survey of 770 families. Developmental Medicine \& Child Neurology 41(12): 834-839

Howlin P and Moore A (1997) Diagnosis in autism a survey of over 1200 patients in the UK. Autism 1(2): 135-162.

Huerta M and Lord C (2012) Diagnostic evaluation of autism spectrum disorders. Pediatric Clinics of North America 59(1): 103-111.

Hutton AM and Caron SL (2005) Experiences of families with children with autism in rural New England. Focus on Autism and Other Developmental Disabilities 20(3): 180-189.

IBM Corp (2013). IBM SPSS Statistics for Windows, Version 22.0. Armonk, NY: IBM Corp.

Jackson S (1994) Educating children in residential and foster care. Oxford Review of Education 20(3): 267-279.

Johnson CP and Myers SM (2007) Identification and evaluation of children with autism spectrum disorders. Pediatrics 120(5): 1183-1215.

Khanna R, Madhavan SS, Smith MJ, Patrick JH, Tworek C and Becker-Cottrill B (2011) Assessment of health-related quality of life among primary caregivers of children with autism spectrum disorders. Journal of Autism and Developmental Disorders 41(9): 1214-1227.

Koegel RL, Schreibman L, Loos LM, Dirlich-Wilhelm H, Dunlap G, Robbins FR and Plienis AJ (1992) Consistent stress profiles in mothers of children with autism. Journal of Autism and Developmental Disorders 22(2): 205-216.

Kozlowski AM, Matson JL, Horovitz M, Worley JA and Neal D (2011) Parents' first concerns of their child's development in toddlers with autism spectrum disorders. Developmental Neurorehabilitation 14(2) 72-78. 
Krauss MW, Gulley S, Sciegaj M and Wells N (2003) Access to specialty medical care for children with mental retardation, autism, and other special health care needs. Metal Retardation 41(5): 329-339.

Landis JR and Koch GG (1977) The measurement of observer agreement for categorical data. Biometrics 33(1): 159-174.

Lickenbrock DM, Ekas NV and Whitman TL (2011) Feeling good, feeling bad: Influences of maternal perceptions of the child and marital adjustment on well-being in mothers of children with an autism spectrum disorder. Journal of Autism and Developmental Disorders 41(7): 848858.

Mandell DS, Novak MM and Zubritsky CD (2005) Factors associated with age of diagnosis among children with autism spectrum disorders. Pediatrics 116(6): 1480-1486.

Mansell W and Morris K (2004) A survey of parents' reactions to the diagnosis of an autistic spectrum disorder by a local service Access to information and use of services. Autism 8(4): 387 407.

McGrew JH and Keyes ML (2014) Caregiver stress during the first year after diagnosis of an Autism Spectrum Disorder. Research in Autism Spectrum Disorders 8(10): 1373-1385.

McMorries CA, Cox E, Hudson M, Liu X and Bebko JM (2013) The diagnostic process of children with autism spectrum disorder: Implications for early identification and intervention. Journal on Developmental Disability 19(2): 42-49.

Meadan H, Halle JW and Ebata AT (2010) Families with children who have autism spectrum disorders: Stress and support. Exceptional Children 77(1): 7-36.

Midence K and O'neill M (1999) The experience of parents in the diagnosis of autism a pilot study. Autism 3(3): 273-285.

Moore K, McConkey R, Sines D and Cassidy A (1999) Improving diagnostic and assessment services for children with autistic spectrum disorders. Early Child Development and Care 154(1): 1-11.

Murphy MA and Ruble LA (2012) A comparative study of rurality and urbanicity on access to and satisfaction with services for children with autism spectrum disorders. Rural Special Education Quarterly 31(3): 3-11.

$\mathrm{Ng} \mathrm{CH}$ (1997) The stigma of mental illness in Asian cultures. Australian and New Zealand Journal of Psychiatry 31(3): 382-390.

Noland RM and Gabriels RL (2004) Screening and identifying children with autism spectrum disorders in the public school system: The development of a model process. Journal of Autism and Developmental Disorders 34(3): 265-277. 
Osborne LA, McHugh L, Saunders J and Reed P (2008) Parenting stress reduces the effectiveness of early teaching interventions for autistic spectrum disorders. Journal of Autism and Developmental Disorders 38(6): 1092-1103.

Palmer RF, Blanchard S, Jean CR and Mandell DS (2005) School district resources and identification of children with autistic disorder. American Journal of Public Health 95(1): 125130.

Rosenberg RE, Landa R, Law JK, Stuart EA and Law PA (2011) Factors affecting age at initial autism spectrum disorder diagnosis in a national survey. Autism Research and Treatment. Available at file://C:/Users/pcm/Downloads/874619\%20(1).pdf

Russell F (2003) The expectations of parents of disabled children. British Journal of Special Educatio 30(3): 144-149.

Sanders JL and Morgan SB (1997) Family stress and adjustment as perceived by parents of children with autism or Down syndrome: Implications for intervention. Child \& Family Behavior Therapy 19(4): 15-32.

Schwartz H and Drager KD (2008) Training and knowledge in autism among speech-language pathologists: A survey. Language, Speech, and Hearing Services in Schools 39(1): 66-77.

Selimoglu O, Ozdemir S, Toret G and Ozkubat U (2013) An examination of the views of parents of children with autism about their experiences at the post-diagnosis period of autism.

International Journal Of Early Childhood Special Education 5(2): 162-167.

Starfield B and Shi L (2004) The medical home, access to care, and insurance: a review of evidence. Pediatrics 113(4): 1493-1498.

Strauss A and Corbin J (1990) Basics of Qualitative Research: Grounded Theory Procedures and Techniques. Newbury Part, CA: Sage.

Strauss A and Corbin J (1994) Grounded theory methodology. Available at https://scholar.google.com/scholar?q=Strauss $+\mathrm{A}+$ and + Corbin $+\mathrm{J}+\% 281994 \% 29+$ Grounded + theo ry + methodology \&btnG $=\& h l=e n \& a s \_s d t=0 \% 2 \mathrm{C} 18$

Stuart M and McGrew JH (2009) Caregiver burden after receiving a diagnosis of an autism spectrum disorder. Research in Autism Spectrum Disorders 3(1): 86-97.

Suchman EA (1965) Stages of illness and medical care. Journal of Health and Human Behavior 6(3): 114-128.

Volkmar FR, Paul R, Klin A and Cohen DJ (Eds.). (2005). Handbook of Autism and Pervasive Developmental Disorders, Diagnosis, Development, Neurobiology, and Behavior (Vol. 1). New Jersey: John Wiley \& Sons.

Wachtel K and Carter AS (2008) Reaction to diagnosis and parenting styles among mothers of young children with ASDs. Autism 12(5): 575-594. 
Ware JE, Kosinski M and Keller SD (1996) A 12-Item Short-Form Health Survey: construction of scales and preliminary tests of reliability and validity. Medical Care 34(3): 220-233.

Westbrook MT, Legge V and Pennay M (1993) Attitudes towards disabilities in a multicultural society. Social Science \& Medicine 36(5): 615-623.

Yirmiya N and Charman T (2010) The prodrome of autism: early behavioral and biological signs, regression, peri-and post-natal development and genetics. Journal of Child Psychology and Psychiatry 51(4): 432-458.

Young RL, Brewer N and Pattison C (2003) Parental identification of early behavioral abnormalities in children with autistic disorder. Autism,7(2): 125-143.

Zimet GD, Powell SS, Farley G K, Werkman S and Berkoff KA (1990) Psychometric characteristics of the Multidimensional Scale of Perceived Social Support. Journal of Personality Assessment 55(3-4): 610-617. 


\section{Table 1.}

Item Factor Loadings for the Obtaining a Diagnosis Questionnaire (ODQ).

Item

Positive Negative Incidental Mean SD Range

1. I was relieved that a diagnosis had been made

.576

.664 behavior

3. I have been able to accept my child's behavior

4. We have been able to adapt family life to my child's behavior

5. I have been able to get practical help for my child

6. Other people have a better understanding of my child's behavior

7. It helped me stop blaming myself

8. I have been able to get support for myself

9. I have become more worried about my child's future

10. Other people do not understand the diagnosis

11. It is difficult to know which problem behaviors are caused by the disorder and which are not

12. I was shocked by the diagnosis

13. My child has been treated worse by other people

14. I was angry about the diagnosis

15. I got the impression that the future was bleak for my child

16. A vague diagnosis makes it difficult to receive help
$0-4$

3.18

$$
1.22 \quad 0-4
$$

$3.17 \quad 1.05 \quad 0-4$

$3.01 \quad 1.07 \quad 0-4$

2.85

$.92 \quad 0-4$

$2.85 \quad 1.04 \quad 0-4$

$2.67 \quad .97$

$0-4$

.420

$2.51 \quad 1.22 \quad 0-4$

$2.49 \quad 1.11 \quad 0-4$

.786

$2.4 \quad 1.31 \quad 0-4$

.477

$1.190-4$

$1.20 \quad 0-4$ 


\begin{tabular}{|c|c|c|c|c|c|c|}
\hline Item & Positive & Negative & Incidental & Mean & SD & Range \\
\hline $\begin{array}{l}\text { 17. I am concerned that other siblings may be } \\
\text { affected }\end{array}$ & & .437 & & 2.13 & 1.33 & $0-4$ \\
\hline $\begin{array}{l}\text { 18. Due to the diagnosis we lowered our } \\
\text { expectations }\end{array}$ & & .512 & & 2.09 & 1.14 & $0-4$ \\
\hline 19. We mourned our "lost child" & & .656 & & 1.9 & 1.44 & $0-4$ \\
\hline 20. Because of the diagnosis, we met other families & - & - & - & 1.6 & 1.31 & $0-4$ \\
\hline 21. We have found autism to be a challenge & & .405 & & 1.54 & .78 & $1-4$ \\
\hline 22. The diagnosis confirmed our feelings & & & .763 & 1.29 & .82 & $0-4$ \\
\hline 23. We already knew that our child had an ASD & & & .610 & 1.15 & 1.21 & $0-4$ \\
\hline 24. We did not face the truth about the diagnosis & & & & 1.14 & 1.02 & $0-4$ \\
\hline 25. Waiting for the diagnosis was very stressful & & 693 & & 1.13 & 1.49 & $0-4$ \\
\hline 26. We asked, "Why us? why our child?" & & .548 & & 0.86 & 1.55 & $0-4$ \\
\hline
\end{tabular}

Note. $\mathrm{N}=78 ;-=$ Item did not load onto any of the subscales 
Table 2.

Actions Taken by Professionals

\begin{tabular}{lcccc}
\hline & & & Refer you to \\
Professional & $\mathrm{N}$ & $\begin{array}{c}\text { Did not think there } \\
\text { was a problem }\end{array}$ & $\begin{array}{c}\text { Provide a } \\
\text { professional }\end{array}$ & $\begin{array}{c}\text { diagnosis } \\
\text { Audiologist }\end{array}$ \\
Behavior interventionist & 3 & $66.7 \%$ & $33.3 \%$ & $0 \%$ \\
Counselor & 3 & $33.3 \%$ & $33.3 \%$ & $33.3 \%$ \\
Developmental Pediatrician & 3 & $66.7 \%$ & $0 \%$ & $0 \%$ \\
General physician & 13 & $13.3 \%$ & $20.0 \%$ & $66.7 \%$ \\
Geneticist & 19 & $45 \%$ & $55 \%$ & $0 \%$ \\
Neurologist & 3 & $10 \%$ & $70 \%$ & $20 \%$ \\
Nurse specialist & 23 & $13.0 \%$ & $30.4 \%$ & $52.2 \%$ \\
Occupational therapist & 3 & $0 \%$ & $100 \%$ & $0 \%$ \\
Organization/Team & 13 & $7.7 \%$ & $53.8 \%$ & $38.5 \%$ \\
Pediatrician & 21 & $14.8 \%$ & $33.3 \%$ & $51.9 \%$ \\
Psychiatrist & 43 & $43.1 \%$ & $51.0 \%$ & $3.9 \%$ \\
Psychologist & 13 & $0 \%$ & $13.3 \%$ & $80.0 \%$ \\
School psychologist/ Educational & 32 & $8.6 \%$ & $14.3 \%$ & $71.4 \%$ \\
evaluator & & $14 \%$ & $0 \%$ & $85.7 \%$ \\
Social worker & 12 & 2 & $0 \%$ & $10 \%$ \\
Speech and language pathologist & 15 & $33.3 \%$ & $46.7 \%$ & $13.3 \%$ \\
Teacher & 4 & $25 \%$ & $75 \%$ & $0 \%$ \\
Therapist & 10 & $10 \%$ & $70 \%$ & $20 \%$ \\
\hline
\end{tabular}


Table 3.

Validation Provided by Professionals

\begin{tabular}{lcc}
\hline Professional & $\mathrm{M}$ & $\mathrm{SD}$ \\
\hline Audiologist & 2.33 & 1.16 \\
Behavior interventionist & 2.67 & .58 \\
Counselor & 2.00 & 1.00 \\
Developmental Pediatrician & 2.73 & .59 \\
General physician & 1.80 & .83 \\
Geneticist & 2.67 & .58 \\
Neurologist & 2.57 & .67 \\
Nurse specialist & 3.00 & .00 \\
Occupational therapist & 2.38 & .65 \\
Organization /Team & 2.63 & .63 \\
Pediatrician & 1.75 & .80 \\
Psychiatrist & 2.60 & .51 \\
Psychologist & 2.60 & .74 \\
School psychologist/ Educational & & .38 \\
evaluator & 2.86 & 1.41 \\
Social worker & 2.00 & .83 \\
Speech and language pathologist & 2.13 & .50 \\
Teacher & 2.75 & .70 \\
Therapist & 2.50 & \\
\hline
\end{tabular}

